\title{
Recent progress of Ammonium chloride as catalyst in organic synthesis
}

\author{
Rammohan Pal \\ Department of Chemistry, Acharya Jagadish Chandra Bose College, \\ 1/1B, A. J. C. Bose Road, Kolkata 700 020, India
}

\begin{abstract}
The role of commercially available Ammonium chloride in organic synthesis can not be understated. This review summarizes the versatile synthetic applications of Ammonium chloride in different chemical transformations. Reactions include Claisen rearrangement, Ullmann coupling, thia-Michael addition, threecomponent synthesis of dihydropyrimidinones, imidazo[1,2-a]pyridines, tetrahydrobenzo[a]xanthene-11-ones, benzoxazines, iminooxazolines, imidazo[1,2-a]pyrimidines, spirochromenes, spiroacridines, four-component synthesis of dipeptides, pyrrolo[3,4-b]pyridine-5-ones, crossed-aldol condensation, condensation of carbonyl compounds and indoles, synthesis of quinoxalines, arylbenzothiazoles, bisbenzothiazoles, reduction, and oxidation. Application of this catalyst allows mild and highly selective transformation and synthesis in a facile and environmentally friendly manner. Moreover, Ammonium chloride is an inexpensive and easily available catalyst, which acts under neutral conditons.
\end{abstract}

Keywords: Ammonium Chloride, Inexpensive, Environmentally Friendly, Acid Catalysis, Organic Synthesis

\section{CONTENTS}

I. Introduction

II. General Information and Structural Features of Ammonium Chloride

III. Claisen Rearrangement

IV. Ullmann Coupling Reaction

V. Thia-Michael Addition Reaction

VI. Multi-Component Reactions (MCR)

VI.I Three-Component Reaction

VI.I.I. Synthesis of dihydropyrimidinones

VI.I.II. Synthesis of imidazo[1,2-a]pyridines

VI.I.III. Synthesis of tetrahydrobenzo[ $\alpha]$ xanthene-11-ones

VI.I.IV.Synthesis of benzoxazines

VI.I.V. Synthesis of iminooxazolines

VI.I.VI. Synthesis of imidazo[1,2-a]pyrimidines

VI.I.VII. Synthesis of spirochromenes and spiroacridines

VI.II. Ugi Four-Component Reaction

VI.II.I. Synthesis of dipeptides

VI.II.II. Synthesis of pyrrolo[3,4- $b]$ pyridine-5-ones

VII.. Condensation Reaction

VII.I. Crossed-aldol condensation reaction

VII.II.Condensation of carbonyl compounds and indoles

VIII. Formation of Nitrogen Heterocycle

VIII.I. Synthesis of quinoxalines

VIII.II. Synthesis of arylbenzothiazoles and bisbenzothiazoles

IX. Reductive Transformations of Organic Substrate

IX.I. Reduction of aromatic nitro compounds to aromatic amines

IX.II. Reduction of azides to amines or amides

IX.III. Reductive cleavage of azo compounds to amines

X. Oxidative Transformation of Alcohol

XI.. Conclusion

Acknowledgement

References 


\section{Introduction}

In the past decade, the chemistry of Ammonium chloride has experienced a rapid development. This growing interest in Ammonium chloride is mainly because of its mild, highly selective properties, environmentally benign character, commercial availability and cost effectiveness. Ammonium chloride is used as fertilizers in crops, an ingredient in fireworks, as a flux in preparing metals to be tin coated, galvanized or soldered. It is used as a expectorant in cough medicine, used as a systematic acidifying agent in treatment of severe metabolic alkalosis, used to maintain the urine at an acid $\mathrm{pH}$ in the treatment of some urinary-tract disordered and treatment on human polymorphonuclear leucocyte iodination. ${ }^{1 \mathrm{a}}$ It is used as food additives, as feed supplementary cattle and an ingredient in nutritive media for yeasts and many microorganism. It has an application as an electrolyte in zinc-carbon batteries, in hair shampoo, in the textile and leather industry. In laboratory it is used to prepare eutective mixture ${ }^{\mathrm{lb}}$ in cooling baths, used to prepare buffer solutions and also mostly used as catalysts for different chemical reactions. Ammonium chloride and Ammonium based chloride compounds ${ }^{1 \mathrm{c}, \mathrm{d}}$ are now being routinely used in organic synthesis as homogeneous as well as heterogeneous acid catalysts for various selective transformations of simple and complex molecules. The purpose of the present review is to summarize the utility of Ammonium chloride with emphasis on recent synthetic applications; Literature coverage is through till 2013.

\section{General Information And Structural Features Of Ammonium Chloride}

Ammonium chloride is white crystalline solid having the following physical properties ${ }^{\text {le }}$

$\begin{array}{ll}\text { Molecular formula } & : \mathrm{NH}_{4} \mathrm{Cl} \\ \text { Molar weight } & : 53.49 \mathrm{~g} / \text { mole } \\ \text { Odor } & : \text { odorless } \\ \text { Melting point } & : 338^{\circ} \mathrm{C}(\text { decomposes }) \\ \text { Boiling point } & : 520^{\circ} \mathrm{C} \\ \text { Solubility in water } & : 297 \mathrm{~g} / \mathrm{L}\left(0^{\circ} \mathrm{C}\right), 372 \mathrm{~g} / \mathrm{L}\left(20^{\circ} \mathrm{C}\right), 773 \mathrm{~g} / \mathrm{L}\left(100^{\circ} \mathrm{C}\right) \\ \text { Solubility in alcohol } & : 6 \mathrm{~g} / \mathrm{L}\left(19^{\circ} \mathrm{C}\right) \\ \text { pH }(1 \% \text { solution/water }) & : 5.5(\text { acidic }) \\ \text { Density } & : 1.5274 \mathrm{~g} / \mathrm{cm}^{3} \\ \text { Refractive index }\left(n_{\mathrm{D})}\right. & : 1.642 \\ \text { Specific gravity } & : 1.53(\text { water }=1)\end{array}$

Figure 1A shows crystalline state of Ammonium chloride. It is hydroscopic and thus highly soluble in water and figure 1B shows the structure of Ammonium chloride where four hydrogen in ammonium ion around the central nitrogen atom must be placed at the four corners of a regular tetrahedron. Aqueous solutions of Ammonium chloride is mildly acidic. It serves as an excellent source of acid and used in various acid catalyzed reactions. It is easy to measure and safe to use.

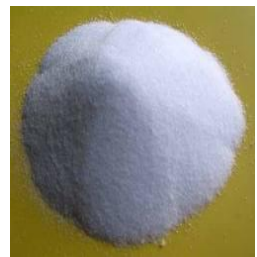

Figure 1A

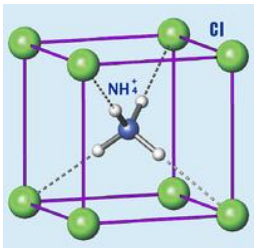

Figure 1B

\section{Claisen Rearrangement}

Ammonium chloride was reported to catalyze aliphatic Claisen rearrangement by Rallis $e$ al. Thus, when allyl 3-allyoxy-2-butenoate $\mathbf{1}$ and crotyl 3-crotyloxy-2-butenoate $\mathbf{2}$ was heated separately at $150{ }^{\circ} \mathrm{C}$ for 10 minutes, the rearrangement accelerates to a small degree by heterogenous catalysis of Ammonium chloride (Scheme 1). ${ }^{2}$ The ethers $\mathbf{1}$ and $\mathbf{2}$ gave allyl 2-allyl-3-oxobutanoate $\mathbf{3}$ and crotyl 2-(1-methyl-2-propenyl)-3oxobutanoate 4 respectively in good yield. The intramolecularity of the rearrangement was also demonstrated by heating a mixture of $\mathbf{1}$ and $\mathbf{2}$ in presence of Ammonium chloride. No crossed products were obtained.

\section{Ullmann Coupling Reaction}

Heng et al. reported that Ammonium chloride could promote palladium-catalyzed Ullmann coupling of aryl bromides in water. A mixture of various aromatic bromides, $\mathrm{Pd} / \mathrm{C}$, zinc, Ammonium chloride and water was stirred at room tempature for 24-72 hrs. yielding diphenyls 5 in $48-67 \%$ yield (Scheme 2). ${ }^{3}$ In absence of 
Ammonium chloride, coupling of aryl bromides mediated by $\mathrm{Pd} / \mathrm{C}$ and zinc the product $\mathbf{5}$ was obtained in very poor yield $\left(17 \%\right.$; when $\mathrm{R}=\mathrm{Me}$ ). In the first step of the mechanism $\mathrm{NH}_{4} \mathrm{CL}$ react with $\mathrm{H}_{2} \mathrm{O}$ yielding $\mathrm{H}^{+}$, which then afforded $\mathrm{H}_{2}$ by reacting with $\mathrm{Zn}$. In presence of $\mathrm{H}_{2}, \operatorname{Pd}(0)$ reacts with aryl bromide or $\mathrm{H}_{2}$ to give intermidiate $6(\mathrm{ArPdBr})$ and intermidiate $7\left[\mathrm{Pd}^{2+}\left(\mathrm{H}^{-}\right)_{2}\right]$, respectively. Intermidiate 6 reacted with another $\mathrm{ArBr}$ to afford the intermidiate $\mathbf{8}$ and $\mathrm{PdBr}_{2}$. Intermidiate $\mathbf{8}$ then underwent reductive elimination to release $\mathbf{5}$ and regenerate the active $\mathrm{Pd}(0)$ species. $\mathrm{PdBr}_{2}$ could also react with $\mathrm{H}_{2}$ to regenerate the active $\mathrm{Pd}(0)$ species. In the meantime, aryl bromide could be reduced by intermidiate 7 to give $\mathrm{ArH}$.

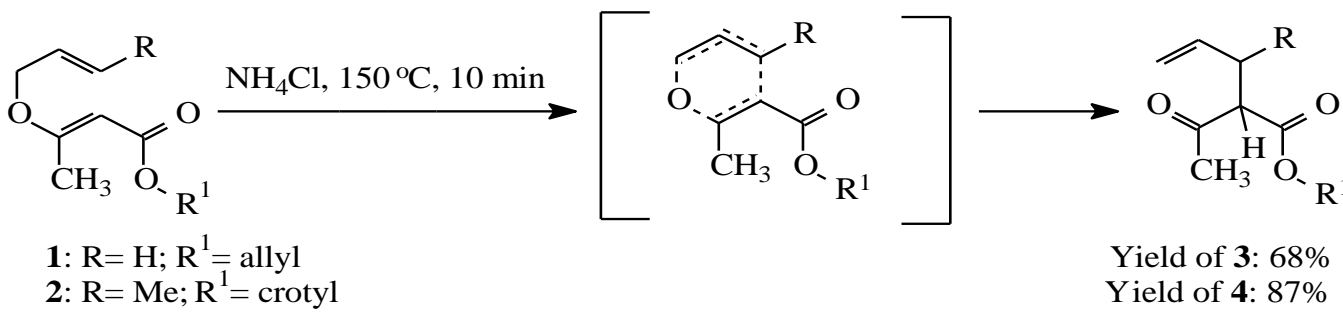

Scheme 1

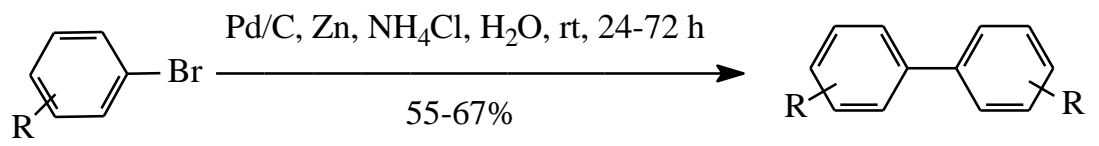

$\mathrm{R}=\mathrm{H}, \mathrm{Me}, \mathrm{OMe}, \mathrm{NMe}_{2}, \mathrm{OH}$

5

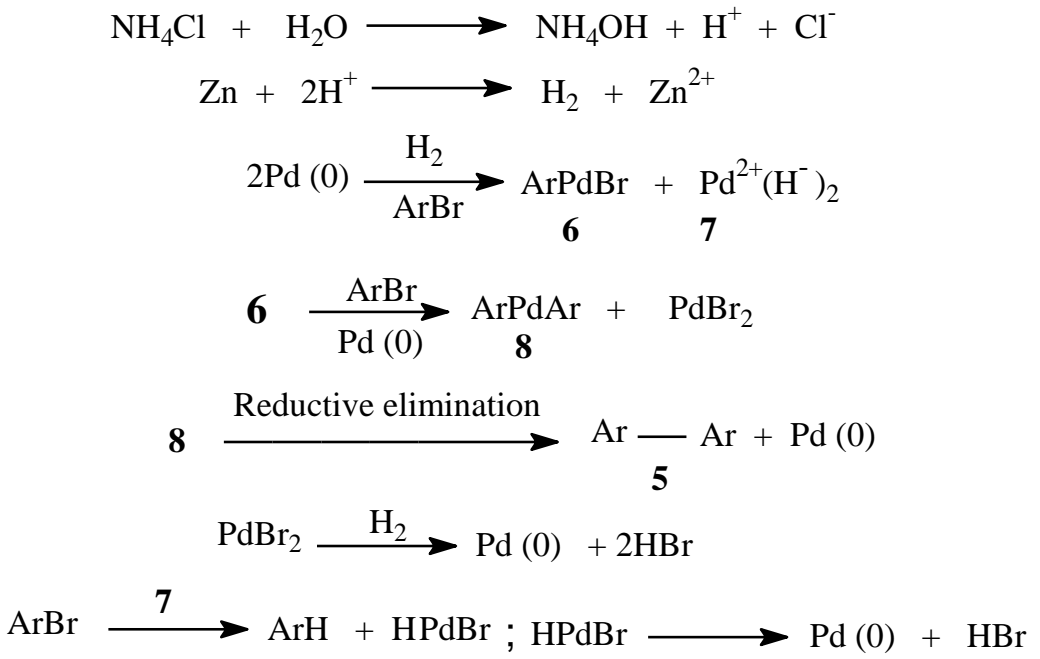

Scheme 2

\section{Thia-Michael Addition Reaction}

'Thia-Michael addition of thiols to $\alpha, \beta$-unsaturated ketones such as chalcones was accomplished in presence of saturated Ammonium chloride in water at room temperature to obtain the corresponding 1,4 adducts 9 in good to excellent yields (Scheme 3). ${ }^{4}$ No by-products resulting from the undesired 1,2-addition and/or bisaddition side reaction were observed. Chalcone derivatives carrying either electron-donating or electronwithdrawing groups did not affect either the yield of the product or the rate of the reaction. This method can also be used to produce $\mathbf{1 0}$ from thiols and $\beta$-nitrostyrenes.

\section{Multi-Component Reaction}

Multicomponent reactions (MCRs), using three or more reactants in a one-pot synthesis to give a single product, has gained synthesis of complicated molecules can be achieved in a fast, efficient, and time-saving manner without the isolation of any intermediates. As a result, it requires minimum effort, which minimizes the 
environmental loading and is an acceptable form of green chemistry. These important three- or four-component reactions have efficiently been performed using Ammonium chloride as catalyst.
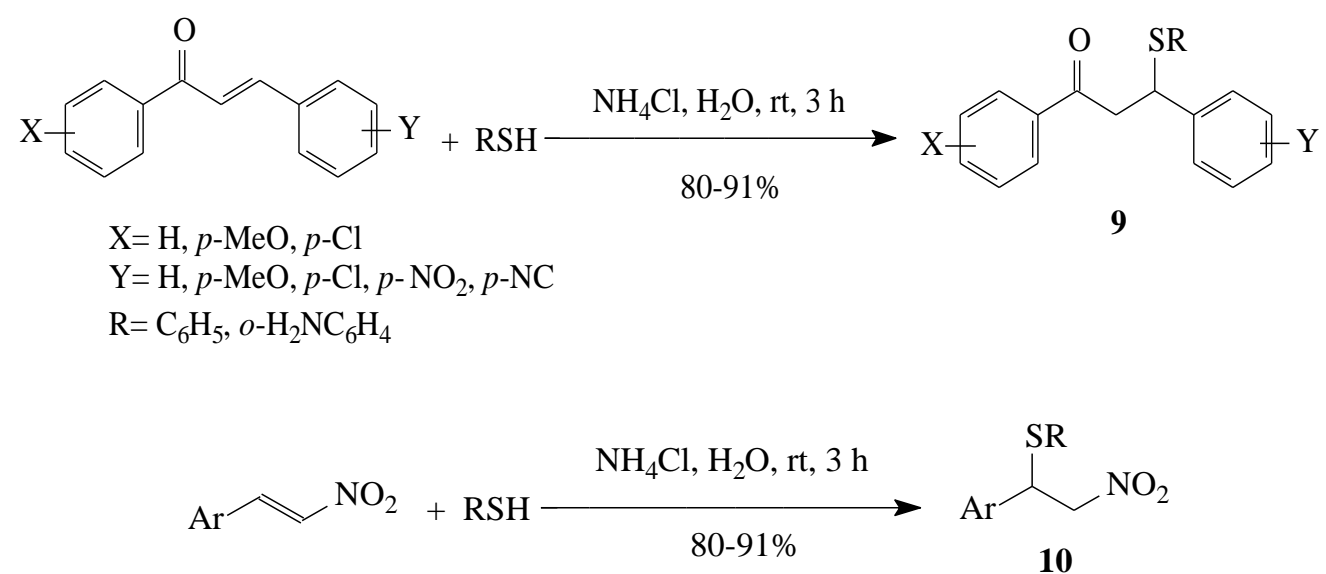

\section{Scheme 3}

VI.I.

Three-component reaction

Three-component reactions of various organic compounds represent a very important class of reactions for forming biologically active heterocyclic compounds. Dihydropyrimidines show antiviral, antitumor, antibacterial activities, ${ }^{5}$ imidazo[1,2-a]pyridines find applications as anticytomegalo-zoster and antivaricellazoster virus, ${ }^{6 a-c}$ analgesic, anti-inflammatory and antipyretic agents, ${ }^{6 \mathrm{~d}-\mathrm{f}}$ benzo $[\alpha]$ xanthenes have been used as anti-inflammatory agents, ${ }^{7 \mathrm{a}}$ and in photodynamic therapy. ${ }^{7 \mathrm{~b}}$ iminobenzoxazine $^{8 \mathrm{a}, \mathrm{b}}$ and iminooxazoline $\mathrm{e}^{8 \mathrm{c}, \mathrm{d}}$ derivatives are very important in the field off pharmaceuticals. Imidazo[1,2-a]pyrimidines ${ }^{9 a, b}$ are medicinally important compounds. Spirochromenes and spiroacridines exhibit spasmolitic, diuretic, anticoagulant, anticancer and antianaphylactic activities. ${ }^{10 \mathrm{a}-\mathrm{c}}$ this is because the synthesis of complicated heterocycles has presently gained tremendous importance. These important heterocycles have efficiently been synthesized using ammonium chloride as catalyst.

\section{VI.I.I. Synthesis Of Dihydropyrimidinones}

Shaabani and coauthors reported an efficient one-pot, three component, Biginelli type synthesis of 3,4dihydropyrimidin-2-(1H)-ones $\mathbf{1 1}$ under solvent-free conditions from aromatic or aliphatic aldehydes, 1,3dicarbonyl compounds and urea or thiourea at $100{ }^{\circ} \mathrm{C}$ using Ammonium chloride as catalyst (Scheme 4). ${ }^{11 a}$ Aliphatic aldehydes which normally show extremely low yields in Biginelli reactions ${ }^{11 \mathrm{~b}}$ gave relatively higher yields of the dihydropyrimidines in presence of Ammonium chloride. Aromatic aldehydes containing either electron-donating or -withdrawing groups underwent the conversion smoothly, giving moderate to excellent yields of 11. Compared with the other methods for multicomponent synthesis of 3,4-dihydropyrimidin-2-( $1 H$ ones, this new method using Ammonium chloride offers better yields, shorter reaction times and economic viability.<smiles>[R]C=[O+][R]C(=O)CC([R])[18F]</smiles>

$\mathrm{R}^{1}=$ Alkyl, Aryl

$\mathrm{R}^{2}=$ Alkyl-O, Alkyl

$\mathrm{R}^{3}=$ Methyl, Phenyl, 2-thienyl<smiles>[X]C(N)N</smiles>

$\mathrm{X}=\mathrm{O}, \mathrm{S}$

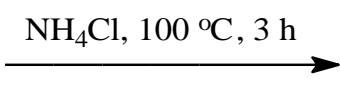

$65-92 \%$<smiles>[R]C(=O)C1=C([R])NC([Y])NC1[R]</smiles>

11

\section{Scheme 4}




\section{VI.I.II. Synthesis Of Imidazo[1,2-a]pyridines}

Shaabani et al. showed that a series of imidazo[1,2-a]pyridine $\mathbf{1 2}$ could be synthesized effectively in 3 hrs. at room temperature by Ammonium chloride catalyzed one-pot, three component Groebke condensation reaction of aromatic aldehydes, isocyanides, and 2-aminopyridines in methanol in 67-96\% yield (Scheme 5). ${ }^{12}$

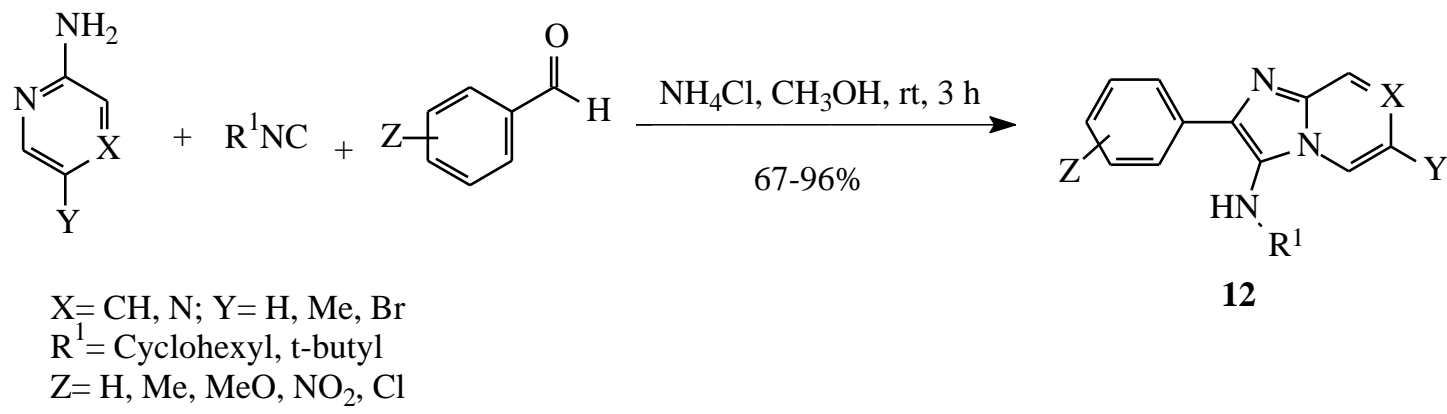

\section{Scheme 5}

Replacing 2-aminopyridine with 2-aminopyrazine afforded 3-aminoimidazo[1,2-a]pyrazine in presence of Ammonium chloride in good yields. Methanol was found to be the best solvent for this reaction. Aromatic aldehydes containing electron withdrawing or electron-donating substituents, gave the product $\mathbf{1 2}$ in good yield.

\section{VI.I.III. Synthesis Of Tetrahydrobenzo[a]xanthene-11-ones}

Foroughifar and his group reported a one-pot multicomponent reaction of aldehydes, dimedones, and 2naphthols for the preparation of 12-alkyl- or 12-alkyl-8,9,10,12-tetrahydrobenzo[ $\alpha]$-xanthene-11-ones 13 using Ammonium chloride as catalyst under solvent-free conditions at $120^{\circ} \mathrm{c}$ (Scheme 6). ${ }^{13}$ Various aromatic aldehydes bearing electron withdrawing groups (such as nitro, halide) and electron-releasing groups (such as methyl, methoxy) showed equal ease towards the product 13. Aliphatic aldehydes also gave the expected product in good yields. When 2-naphthol was replaced by 6-bromo-2-naphthol or 2,7-naphtholenediol under similar conditions the corresponding tetrahydrobenzo[ $\alpha]$ xanthene-11-ones $\mathbf{1 3}$ was obtained in good to excellent yields.

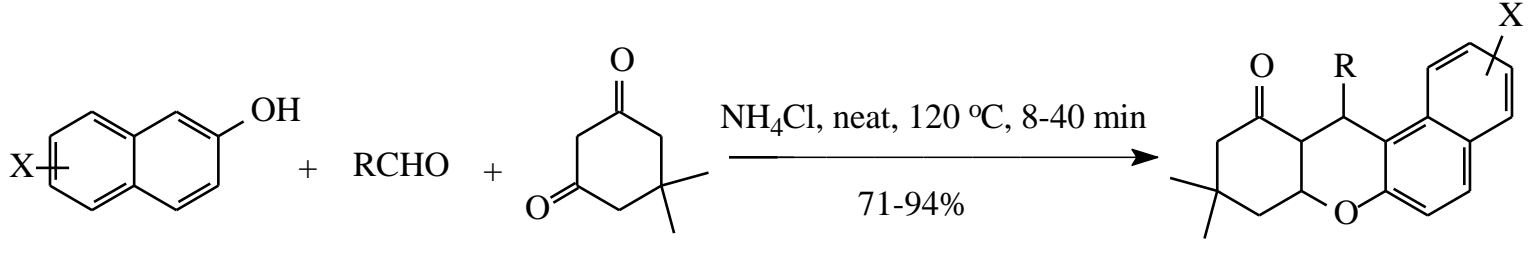

$\mathrm{X}=\mathrm{H}, \mathrm{Br}, \mathrm{OH}$

13

$\mathrm{R}=$ Phenyl, aryl, alkyl, cinnamyl

\section{Scheme 6}

\section{VI.I.IV. Synthesis Of Benzoxazines}

Bonne and his groups synthesized 4-imino-4H-3,1-benzoxazines 17 in presence of Ammonium chloride in good to excellent yields using a three component reaction sequence. Heating a toluene solution of an isonitrile 14, an amine 15, and an aldehyde $\mathbf{1 6}$ in presence of a stoichiometric amount of Ammonium chloride at $60{ }^{\circ} \mathrm{C}$ for $12 \mathrm{hrs}$. produced 17 in 53-91\% yield (Scheme 7). ${ }^{14}$ Although, the reaction takes place at room temperature but the yield is low and requires longer times. A plausible reaction mechanism that accounts for the preparation of $\mathbf{1 7}$ was shown in scheme 7. Thus, condensation of $\mathbf{1 5}$ and $\mathbf{1 6}$ gave the iminium 18, which reacted with isonitrile $\mathbf{1 4}$ to afford the nitrilium intermediate 19. Trapping of the latter by the internal amide oxygen produced the 4-iminobenzoxazine 17. Formation of quinazolin-4-ones 20, which could result from the nucleophilic addition of amide nitrogen to the nitrilium intermidiate, was not observed. 


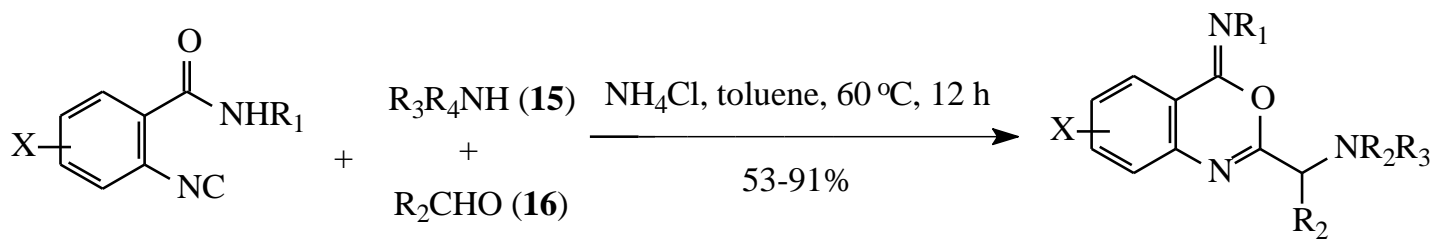

14

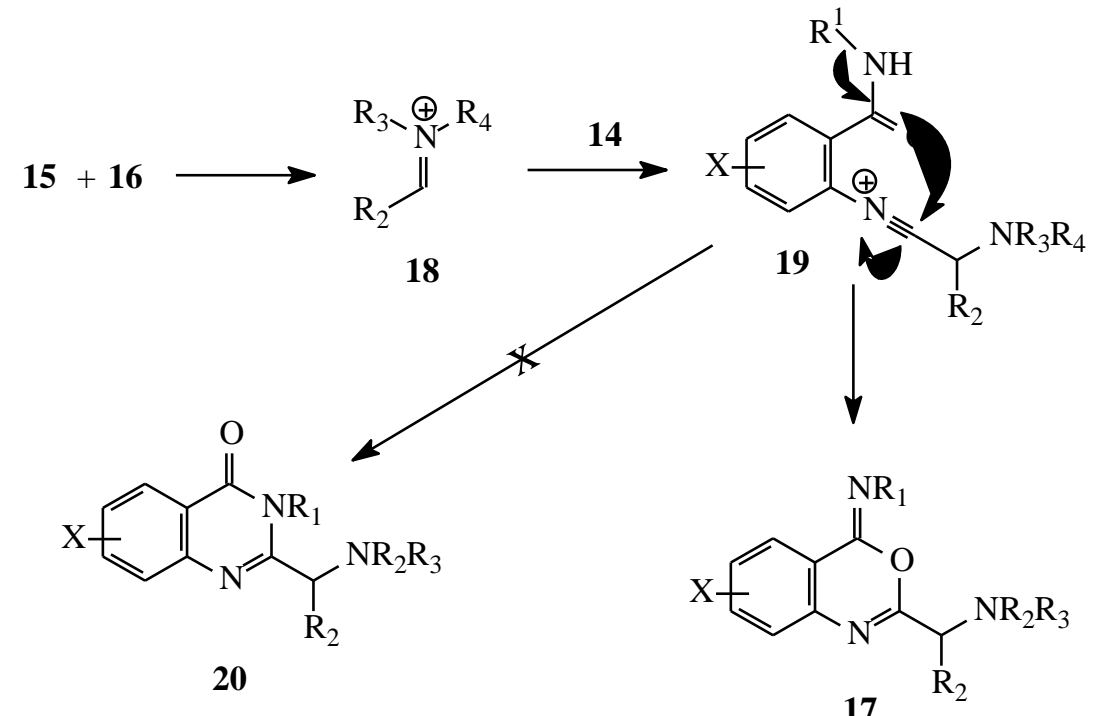

Scheme 7

VI.I.V. Synthesis Of Iminooxazolines

A new three-component synthesis of 5-iminooxazolines $\mathbf{2 4}$ starting from aldehydes, amines,, and $\alpha, \alpha$-disubstituted- $\alpha$-isocyanoacetamides using Ammonium chloride were developed by Pirali et al. Thus, when heptanal 21 morpholine 22, and $\alpha$-isocyanoacetamide 23 were refluxed at $60{ }^{\circ} \mathrm{C}$ in toluene using Ammonium chloride $\mathbf{2 4}$ was obtained in $62 \%$ yield (Scheme 8 ). ${ }^{15}$ Condensation of $\mathbf{2 1}$ and $\mathbf{2 2}$ gave the iminium ion $\mathbf{2 5}$, which reacted with isonitrile $\mathbf{2 3}$ to afford the nitrilium intermidiate $\mathbf{2 6}$. Trapping of the latter by the internal amide oxygen produced 24.

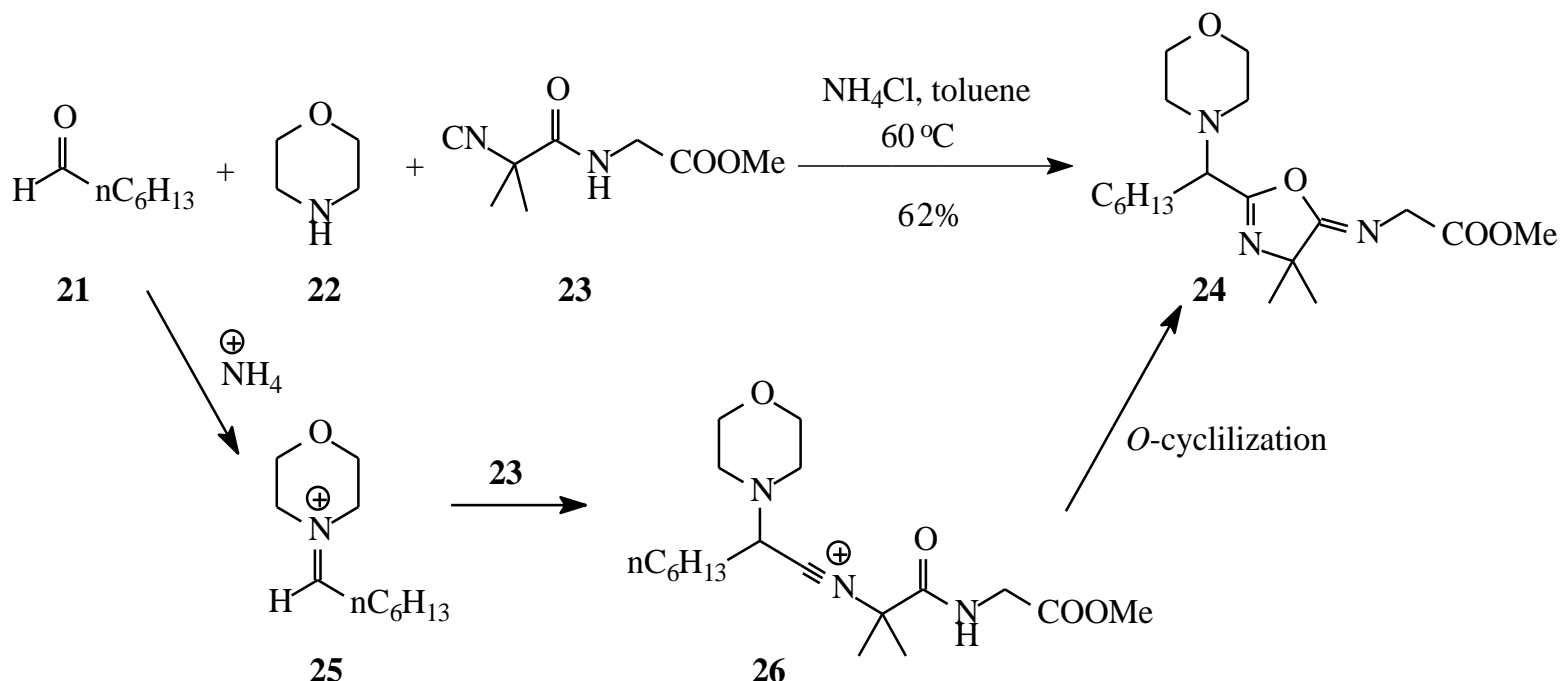

Scheme 8

VI.I.VI. Synthesis Of Imidazo[1,2-a]Pyrimidines

Parchinsky et al. ${ }^{16}$ reported that various novel imidazo[1,2-a]pyrimidines $\mathbf{2 8}$ were synthesized in 49$60 \%$ yield via a multicomponent reaction of 2-aminopyrimidine, aromatic aldehyde, and isonitrile in presence of 
Ammonium chloride in refluxing toluene (Scheme 9). The use of a nonpolar solvent instead of polar solvents like methanol, suppresses formation of multiple products.

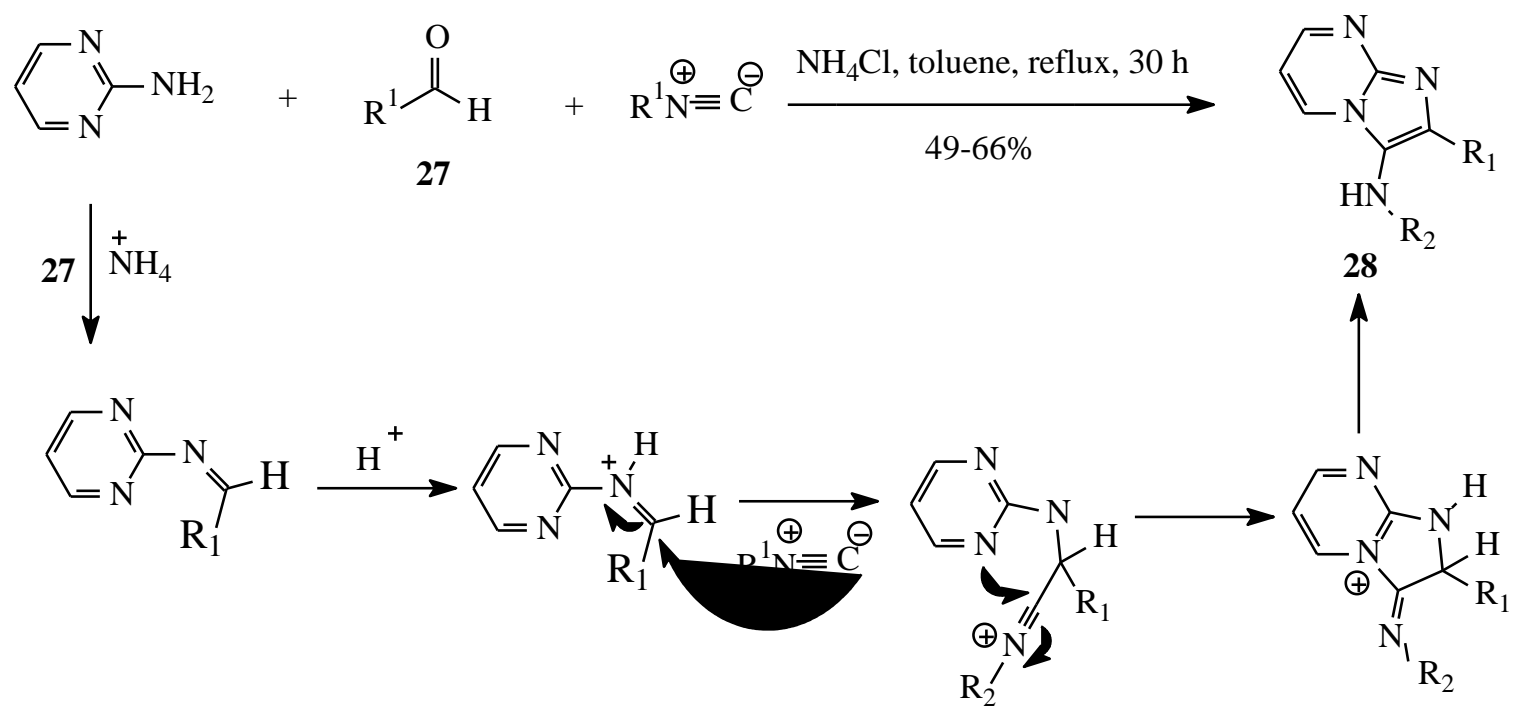

Scheme 9

\section{VI.I.VII. Synthesis Of Spirochromenes And Spiroacridines}

Dabiri et al. ${ }^{17}$ reported that various novel functionalized spirocromenes $\mathbf{3 2}$ and $\mathbf{3 4}$ were synthesized in good to excellent yields via a multicomponent reaction of isatin $\mathbf{3 0}$ or acenapthoquinone 33, an activated methylene reagent $\mathbf{3 1}$ and 1,3-dicarbonyl compounds $\mathbf{2 9}$ in presence of catalytic amount of Ammonium chloride in water at $80{ }^{\circ} \mathrm{C}$ (Scheme 10). The most probable mechanism of this reaction include a fast Knoevenagel condensation between isatin and $\mathrm{CH}$-acidic malononitrile/ethyl cyanoacetate in presence of Ammonium chloride in water in the first step and a Michael addition of diketones to the unsaturated nitrile, the product of knoevenagel condensation, in the second step and then the cycloaddition of the hydroxyl group to the cyano moiety to form the desired product. When benzyl cyanide was treated as a substitute of malononitrile or ethyl cyanoacetate in this reaction under similar conditions spiroacridine derivatives were produced with prolonged reaction times.

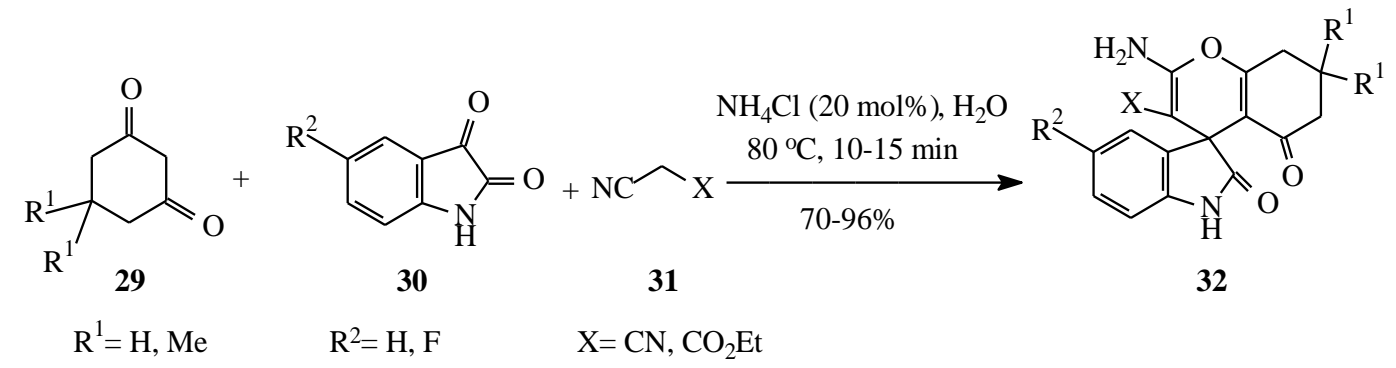<smiles>[R]C1([R])CC(=O)CC(=O)C1</smiles>

29

$\mathrm{R}^{1}=\mathrm{H}, \mathrm{Me}$<smiles>O=C1C(=O)c2cccc3cccc1c23</smiles>

33<smiles>[X]CC=[N+]</smiles>

$\mathrm{NH}_{4} \mathrm{Cl}(20 \mathrm{~mol} \%), \mathrm{H}_{2} \mathrm{O}$ $80{ }^{\circ} \mathrm{C}, 10-15 \mathrm{~min}$<smiles>[X]C1=C(N)OC2=C(C(=O)CC([R])([R])C2)C12C(=O)c1cccc3cccc2c13</smiles>

34 


\section{VI.II. Ugi Four-Component Reaction}

The Ugi reaction ${ }^{18 \mathrm{a}-\mathrm{c}}$ is a four-component reaction of a ketone or aldehyde, an amine, an isocyanide and a carboxylic acid to rapidly prepare $\alpha$-aminoacyl amide derivatives. The Ugi reaction products can exemplify a wide variety of substitution patterns, and constitute peptidomimetics that have potential pharmaceutical applications viz. Crixivan, ${ }^{18 \mathrm{~d}}$ a protease inhibitor used as a component of highly active antiretroviral therapy (HAART) to treat HIV infection and AIDS, Lidocaine ${ }^{18 \mathrm{e}}$ and bupivacaine ${ }^{18 \mathrm{f}}$ a caine-type anesthetics, in conjugation with the enabling technologies such as high-throughput screening and combinatorial chemistry. ${ }^{18 g}$

\section{VI.II.I. Synthesis Of Dipeptides}

Cristau et al. reported a Ugi four-component reaction promoted by Ammonium chloride in aprotic solvent. Thus, stirring a mixture of an aldehyde, amine, 3-hydroxyphenyl acetic acid, isonitrile and Ammonium chloride in dry toluene at $60{ }^{\circ} \mathrm{C}$ for specified time afforded dipeptide amide 35 in good yield (Scheme 11). ${ }^{19}$

Ammonium chloride promoted synthesi of dipeptides $\mathbf{3 6}$ using Ugi four-component reaction was also reported by Bonne and his coworkers. Morpholine, heptanal, potassium 2-isocyano-3-phenylpropanoate and Ammonium chloride were stirred in toluene at room temperature for $18 \mathrm{hrs}$. producing the dipeptide in $90 \%$ yield as a mixture of two diastereoisomers (Scheme 12). ${ }^{20}$

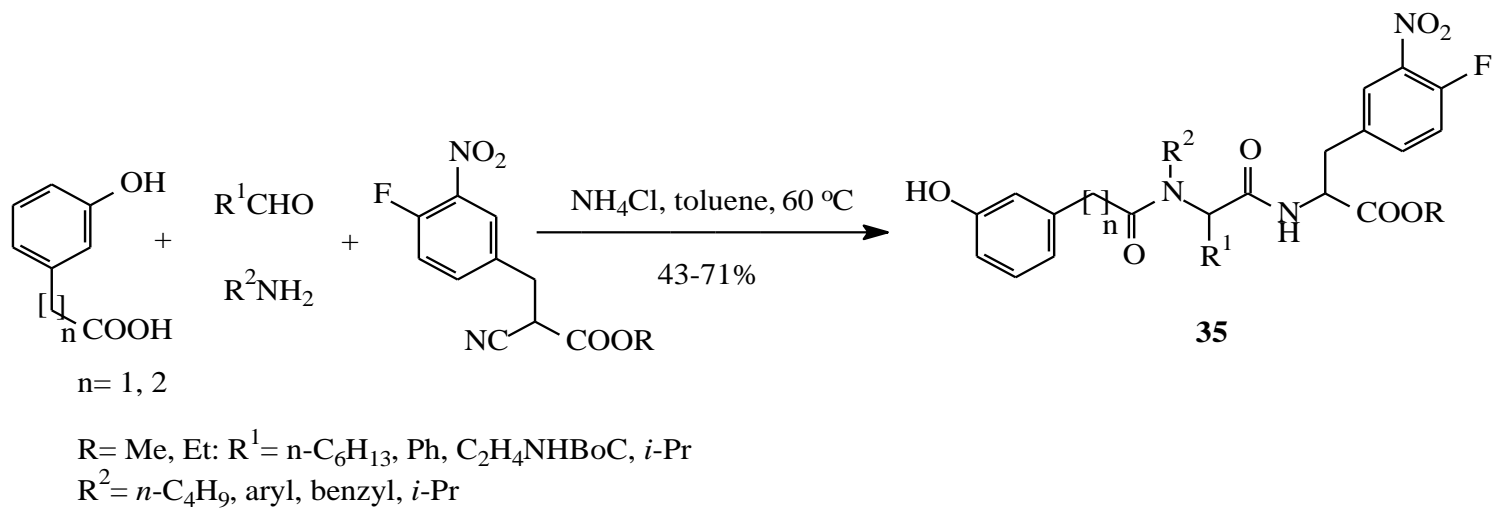

\section{Scheme 11}
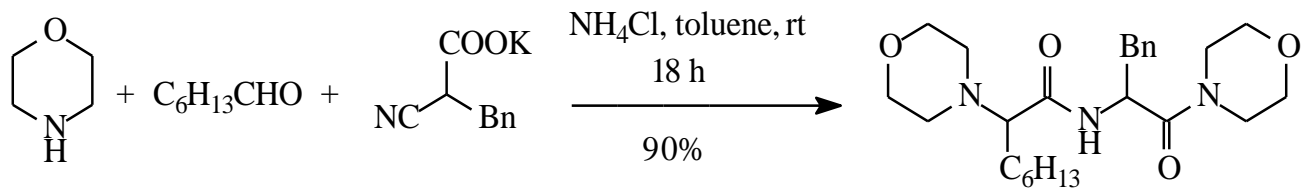

Scheme 12

\section{VI.II.II. Synthesis Of Pyrrolo[3,4-b]Pyridine-5-Ones}

Janvier and his group reported a one-pot Ugi four-component synthesis of pyrrolo[3,4-b]pyridine-5ones 40 using Ammonium chloride. A solution of an aldehyde, an amine, and an isonitrile $\mathbf{3 7}$ was stirred in presence of Ammonium chloride at room temperature, giving oxazole 39 through imine intermidiate 38. Subsequently, treatment of acyl chloride gave the product $\mathbf{4 0}$ in good yield (Scheme 13). ${ }^{21}$ Ammonium chloride provided a proton source that is able to form hydrogen bond with $\mathbf{3 8}$ favoring subsequent nucleophilic attack of isonitrile.

\section{Condensation Reaction}

Cross-aldol condensation of aldehydes with ketones is an important reaction for the synthesis of $\alpha, \beta$ unsaturated carbonyl compounds, which are known to show diverse biological activities. ${ }^{22 a-c}$ These types of compounds are used as intermediates for synthesis of various pharmaceuticals, agrochemicals and perfumes. ${ }^{23 a, b}$ On the other hand condensation of carbonyls and indoles give diindolylmethanes that show a wide variety of biological activities. ${ }^{24}$ It was found that Ammonium chloride effectively catalyses both types reactions. 
<smiles>[R]C([R])[R]</smiles>

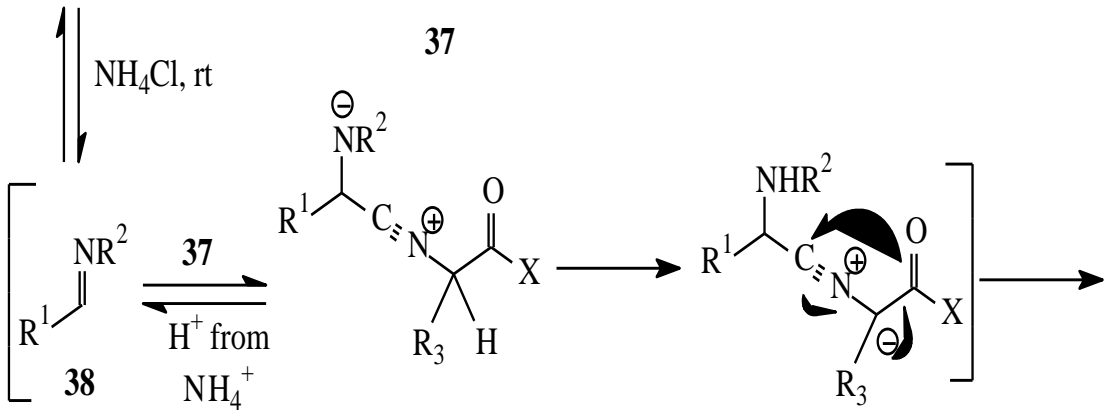<smiles>[R]NC([R])c1nc([R])c([X])o1</smiles><smiles>CC(C)(C)OC(=O)/C=C/C(=O)Cl</smiles><smiles>[R]c1nc2c(c(C(=O)OCC)c1O)C(=O)N([R])C2[R]</smiles>

40<smiles>[R]C1=NC2=C(C(=O)N([R1])C2)C(C(=O)OCC)C([R])C1=O</smiles><smiles>[R]c1nc(C([R])N([R])C(=O)/C=C\C(=O)OCC)oc1[X]</smiles>

\section{Scheme 13}

\section{VII.I. Crossed-Aldol Condensation Reaction}

Teimouri and co-workers have reported that Ammonium chloride acts as an excellent catalyst for the cross-aldol condensation reaction. Thus, when cycloalkanones and various aromatic aldehydes were refluxed in ethanol in presence of Ammonium chloride for 3.5-5 h., $\alpha, \alpha^{\prime}$-bis(arylmethylene)cycloalkanones 41, was furnished in excellent yields (Scheme 14) ${ }^{25 a}$ Fufuraldehyde and cinnamaldehyde also gives excellent yields of the corresponding condensation products. Microwave irradiation method ${ }^{25 b}$ for the synthesis of the similar type of compounds using ammonium chloride has also been reported in very short time.

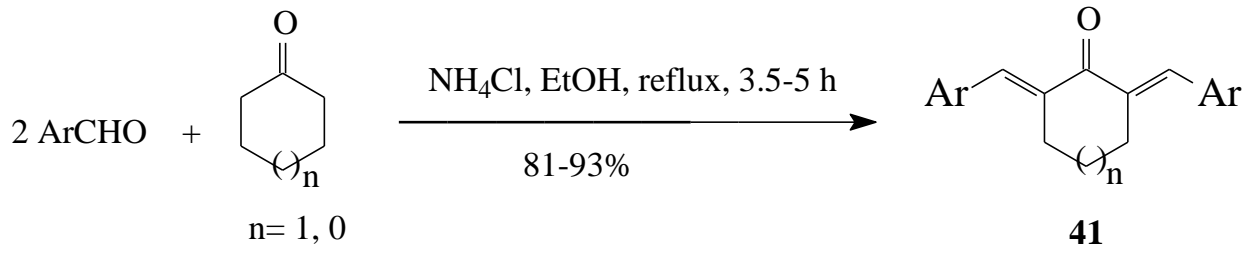

$\operatorname{Ar}=$ phenyl, furyl, aryl and cinnamyl

\section{Scheme 14}

\section{VII.II. Condensation Of Carbonyl Compounds And Indoles}

Ammonium chloride was utilized by Azizian and his groups to condense carbonyl compounds with indoles for the synthesis of diindolylmethanes $\mathbf{4 2}$ under solvent-free conditions. Thus, when a mixture of carbonyl compound, indole and Ammonium chloride was heated with stirring at $90{ }^{\circ} \mathrm{C}, \mathbf{4 2}$ was formed in good 
to excellent yield (Scheme 15). ${ }^{26}$ Aromatic and heteroaromatic aldehydes as well as cinnamaldehyde also gave excellent yields. However, aliphatic aldehydes such as acetaldehyde and butaraldehyde gave somewhat lower yields due to rapid evaporation at $90{ }^{\circ} \mathrm{C}$. Both aliphatic and aromatic ketones required increasingly more time for completion of the reaction and their yields were relatively low due to steric crowding in the resulting diindolylmethanes.

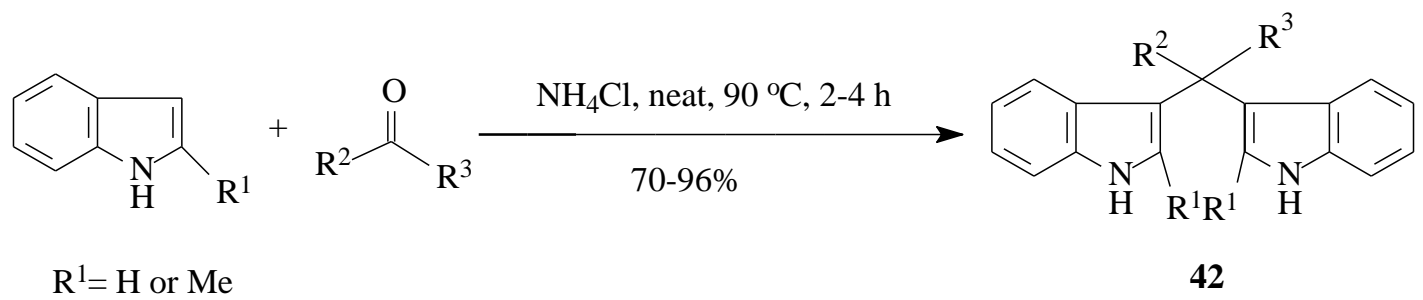

\section{Scheme 15}

\section{Formation Of Nitrogen Heterocycle}

\section{VIII.I. Synthesis Of Quinoxalines}

Quinoxalines, well known for their wide spectrum of biological activities ${ }^{27 a-d}$ ranging from antihelmintic, anticancer, antimicrobial, to antibacterial antiinflamatory and antidepressant, was synthesized effectively by Darabi et al. by the direct condensation of various benzene-1,2-diamines and 1,2-dicarbonyl compounds in excellent yields (95-100\%) at room temperature using Ammonium chloride in methanol as a mild, eco-friendly acid free and metal free catalyst (Scheme 16). ${ }^{28}$

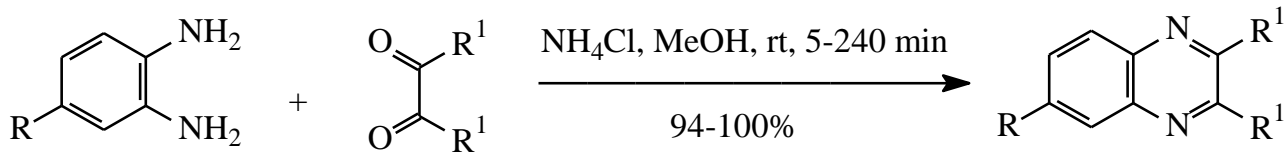

$\mathrm{R}=\mathrm{H}, \mathrm{Me}, \mathrm{NO}_{2}, \mathrm{Cl}$

$\mathrm{R}^{1}=$ alkyl, aryl

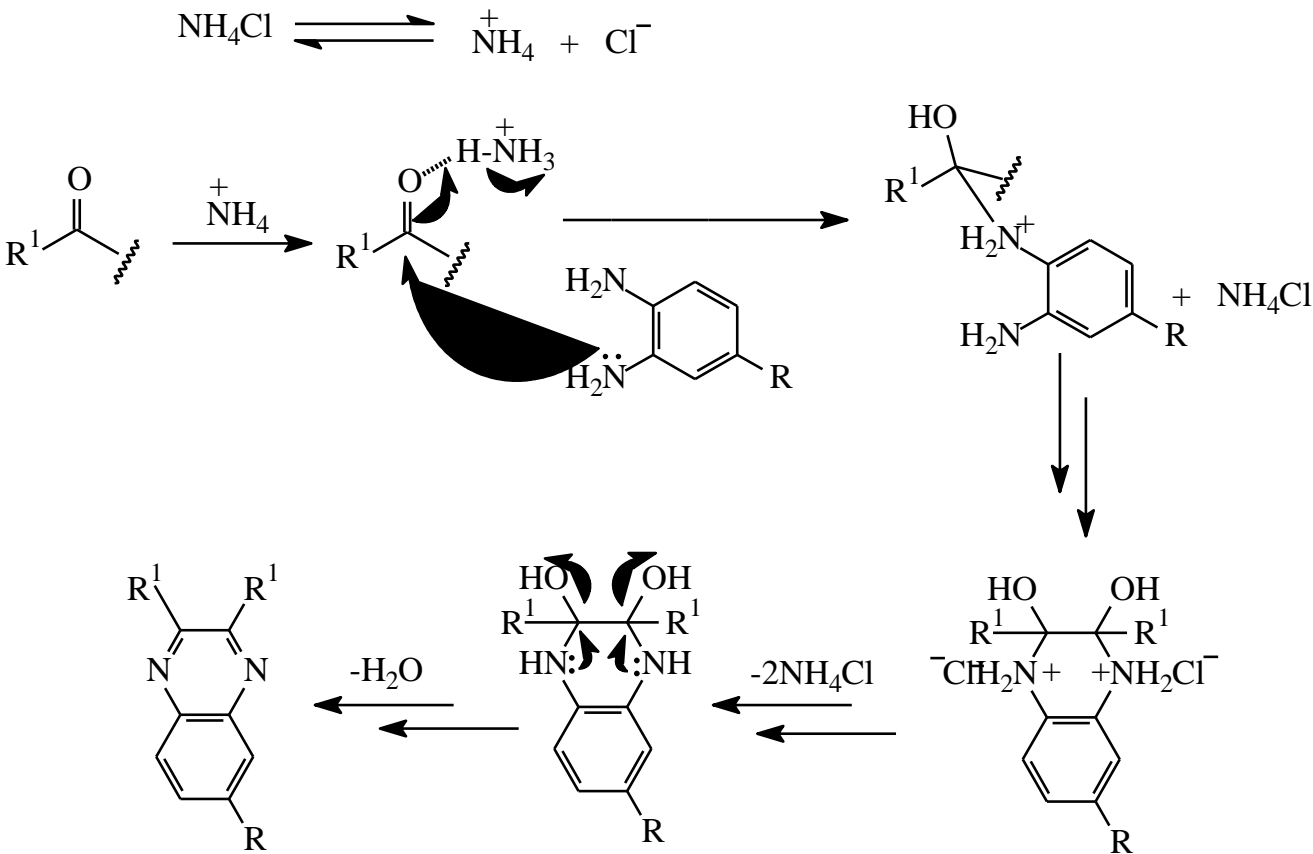

Scheme 16 


\section{VIII.II. Synthesis Of Arylbenzothiazoles And Bisbenzothiazoles}

Maleki et al. synthesized 2-arylbenzothiazoles, ${ }^{29 a-c}$ a class of potent antitumor compounds by the simple condensation of 2-aminothiophenol with aromatic aldehydes at room tempeture using Ammonium chloride as catalyst and benign methanol-water as the reaction medium (Scheme 17). ${ }^{30}$ The reaction stopped at the benzothiazoline derivative when carried out under nitrogen atmosphere thus proving that aerial oxygen is absolutely essential for the oxidation step.

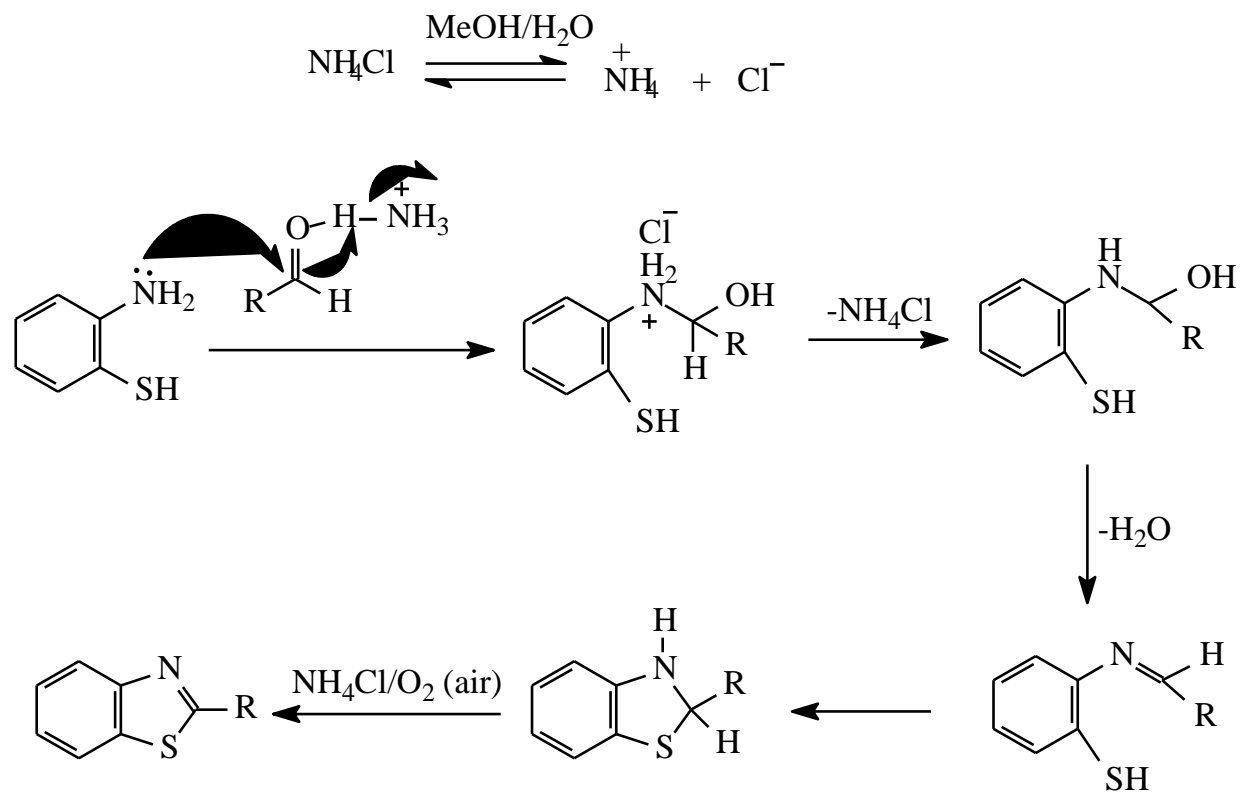

Scheme 17

IX. Reductive Transformation Of Organic Substrates

IX.I. Reduction Of Aromatic Nitro Compounds To Aromatic Amines

Ammonium chloride was used for the ultrasound-promoted highly efficient chemoselective reduction of aromatic nitro compounds to the corresponding amine compounds in 56-90\% yield. For example, 6-nitro chrysene $\mathbf{4 3}$ was reduced to the 6-amino chrysene $\mathbf{4 4}$ in $86 \%$ yield in presence of samarium metal and Ammonium chloride in methanol under ultrasonication at room temperature (Scheme 18). ${ }^{31 a}$ In absence of Ammonium chloride the reduction did not take place, inspite of keeping all other conditions identical. The reduction sensitive groups, viz. bromo, cyano, ester, unsaturated bond and heterocyclic ring remained unaffected during this transformation.<smiles>O=[N+]([O-])c1cc2c3ccccc3ccc2c2ccccc12</smiles>

43
$\mathrm{Sm} / \mathrm{NH}_{4} \mathrm{Cl}, \mathrm{MeOH}, \mathrm{US}, \mathrm{rt}, 10 \mathrm{~min}$<smiles>Nc1cc2c3ccccc3ccc2c2ccccc12</smiles>

Scheme 18
44

Similar type of chemoselective reduction of aryl nitro compounds like nitrophenols to corresponding aminophenols was reported by Sridharan et al. ${ }^{3 \mathrm{~b}}$ using zinc and Ammonium chloride in aqueous medium at room temperature (Scheme 19). 


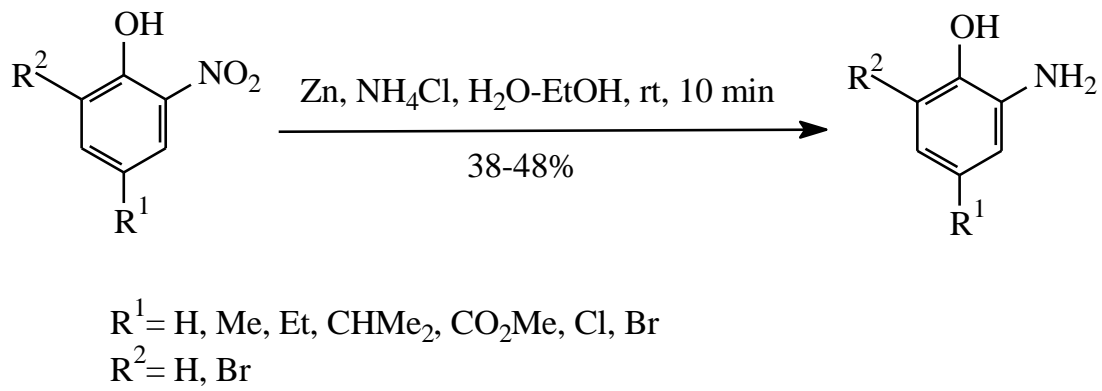

Scheme 19

IX.II. Reduction Of Azides To Amines Or Amides

Ammonium chloride in combination with zinc was used to reduce alkyl and acyl azides to the corresponding amines or amides in good to excellent yields (86-98\%) at room temperature as well as under refluxing conditions. Thus, when a mixture of acyl azide $\mathbf{4 5}$ and Ammonium chloride in ethyl alcohol and water, zinc powder was stirred vigorously at room temperature, $\mathbf{4 6}$ was formed in $98 \%$ yields (Scheme 20). ${ }^{32}$ Functional groups such as $\mathrm{C}=\mathrm{C}$ bond, benzyl, esters etc. which were easily destroyed during hydrogenation could tolerate this method and also no racemisation was observed in case of the reduction of optically active azides.

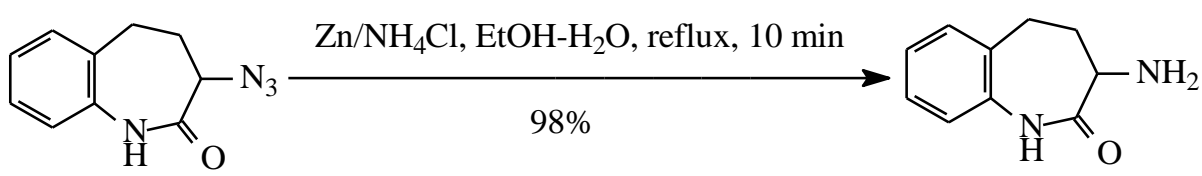

Scheme 20

IX.III. Reductive Cleavage Of Azo Compounds To Amines

The combination of Ammonium chloride and zinc in methanol was further used by Sridhara et al. for the reductive cleavage of azo compounds to their corresponding anilines (Scheme 21) ${ }^{33}$, reaction time being 5-20 minutes at room temperature. The reaction however, did not proceed in absence of Ammonium chloride. Azo compounds bearing electron donating groups such as $\mathrm{OCH}_{3}, \mathrm{OH}, \mathrm{CH}_{3}$ and electron-withdwraing groups such as $\mathrm{COOH}, \mathrm{COCH}_{3}$ and halogens remained unaffected during the cleavage step.

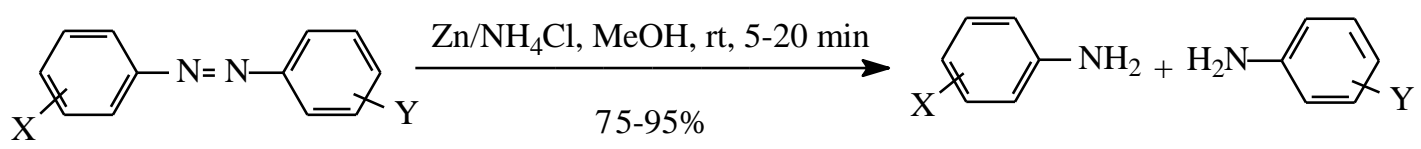

$\mathrm{X}$ or $\mathrm{Y}=\mathrm{H}, \mathrm{MeO}, \mathrm{OH}, \mathrm{Me}$,

$\mathrm{COOH}, \mathrm{COMe}$, halogen

\section{Scheme 21}

\section{Oxidative Transformation Of Alcohols}

An efficient procedure for the oxidation of alcohols with Ammonium chloride in the presence of catalytic amount of $\mathrm{NaBrO}_{3}$ has been developed in the recent years. An optimized protocol, published in Journal of Chemical Research $(S)$ for the oxidation of secondary alcohol $\mathbf{4 7}$ to corresponding ketone $\mathbf{4 8}$ (Scheme 22), ${ }^{34}$ consists of the treatment of the alcohol $\mathbf{4 7}$ in aqueous acetonitrile with Ammonium chloride and $\mathrm{NaBrO}_{3}$ at $80^{\circ} \mathrm{C}$. This procedure involves a very high degree of selectivity for the oxidation of benzylic alcohol to aldehydes, without any noticeable overoxidation to carboxylic acids, and high chemoselectivity in presence of either secondary alcohols or other oxidizable moieties. 


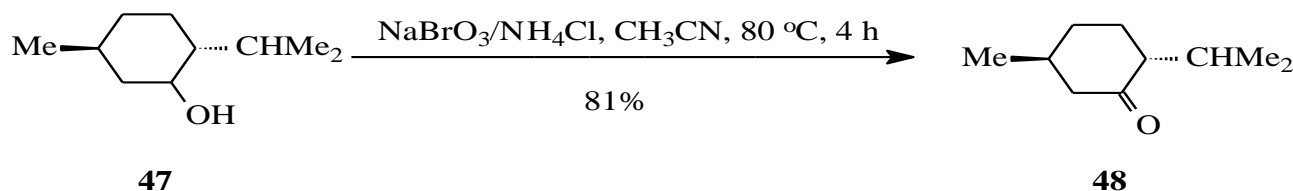

\section{Scheme 22}

\section{Conclusion}

This review demonstrates an active current interest in synthetic applications of Ammonium chloride as catalyst. ${ }^{35-39}$ This growing interest of Ammonium chloride is mainly due to their very useful acidic properties, combined with benign environmental character, inexpensive and commercial availability. There has been a major surge of catalytic activity in several areas of the Ammonium chloride chemistry. These areas include the application of Ammonium chloride catalysts in various organic transformations such as formation of C-C, C-N, C-O, C-P, C-S and N-H bonds in different synthetically important compounds. We anticipate that these areas of Ammonium chloride chemistry will continue to attract significant research activity in the future.

\section{Acknowledgement}

I gratefully acknowledge the funding support of this work from the Authorities of Acharys Jagadish Chandra Bose College and the Minor Research Projecr(S) No. PSW-130/11-12 (ERO) by the University Grants Commission, New Delhi, India.

\section{Reference}

[1]. (a) Phillips, W. A.; Hosking, C. S.; Shelton, M. J.; J. Clin. Pathol. 1983, 36, 808. (b) Shamsuri, A. A.; Abdullah, D. K. International J. Chem. 2011, 3, 161. (c) Karuvalam, R. P.; Divia, S. M.; Haridas, K. R. J. Korean Chem. Soc. 2010, 54, 589. (d) Xu, L.-W.; Li, J.W.; Zhou, S.-L.; Xia, C.-G. New J. Chem. 2004, 28, 183. (e) Hawley, G. G. The Sigma Algrich Library of Chemical Safety Data, Edition II, 2005.

[2]. Rallis, J. W.; Lundin, R. E.; Bailey, G. F. J. Org. Chem. 1963, 28, 3521.

[3]. Li, J.-H.; Liang, Y.; Liu, W.-J.; Tang, S.; Xie, Y.-X. Chin. J. Chem. 2004, 22, 1432.

[4]. Chen, W.-Y.; Shi, L. Catal. Commun. 2008, 9, 1079.

[5]. Kappe, C. O. Tetrahedron 1993, 49, 6937.

[6]. (a) Gueiffier, A; Lhassani, M.; Elhakmaoui, A.; Snoeck, R.; Andrei, G.; Chavignon, O.; Teulade, J. C.; Kerbal, A.; Essassi, E. M.; Debouzy, J. C.; Witvrouw, M.; Blache, Y.; Balzarini, J.; De Clercq, E.; Chapat, J. P. J. Med. Chem. 1996, 39, 2856. (b). Gueiffier, A; Mavel, S.; Lhassani, M.; Elhakmaoui, A.; Snoeck, R.; Andrei, G.; Chavignon, O.; Teulade, J. C.; Witvrouw, M.; Balzarini, J.; De Clercq, E.; Chapat, J. P. J. Med. Chem. 1998, 41, 5108. (c) Mavel, S.; Renou, J. L.; Galtier, C.; Snoeck, R.; Andrei, G.; Balzarini, J.; De Clercq, E.; Gueiffier, A; Arzneim Forsch 2001, 51, 304. (d) Abignente, E. Actual Chim. Ther. 1991, 18, 193. (e) Abignente, E.; Arena, F.; Lurachi, E.; Saturnino, C.; Rossi, F.; Lampa, E.; Cazzola, M.; Brandinelli, E.; Marrazzo, R.; Marmo, E. Rend. Atti. Accad. Sci. Med. Chir. 1985, 139, 313. (f) Almirante, L.; Polo, L.; Mugnaini, A.; Provinciali, E.; Rugarli, P.; Biancotti, A.; Gamba, A.; Murmann, W. J. Med. Chem. 1965, 8, 305.

[7]. (a) Poupelin, J. P.; Ruf, G. S.; Blanpin, O. F.; Narcisse, G.; Ernouf, G. U.; Lacroix, R. Eur. J. Med. Chem. 1978, 13, 67. (b) Ion, R. M.; Planner, A.; Wiktorowicz, K.; Frackowiak, D. Acta Biochim. Pol. 1998, 45, 833.

[8]. (a) Molina, P.; Alajarin, M.; Vidal, A.; Foces-Foces, M.; Cano, F. H. Tetrahedron 1989, 45, 4263. (b) Selby, T. P.; Birch, L. D. WO Patent 03/032731 A1, 2003; Chem. Abstr. 2003, 138: 316207. (c) Middleton, W. J.; Krespan, C. G. J. Org. Chem. 1968, 3625. (d) Koksch, B.; Mutze, K.; Osipov, S. N.; Golubev, A. S.; Burger, K. Tetrahedron Lett. 2000, 41, 3825.

[9]. (a) Rival, Y.; Grassy, G.; Michel, G. Chem. Pharm. Bull. 1992, 40, 1170. (b) Rival, Y.; Taudou, A.; Ecalle, R. Farmaco 1993, 48, 857.

[10]. (a) Skommer, J.; Wlodkowic, D.; Matto, M.; Eray, M.; Pelkonen, J. Leuk. Res. 2006, 30, 322. (b) Andreani, L. L.; Lapi, E. Boll. Chim. Farm. 1960, 99, 583. (c) Bonsignore, L.; Loy, G.; Secci, D.; Calignano, A. Eur. J. Med. Chem. 1993, $28,517$.

[11]. (a) Shaabani, A.; Bazgir, A.; Teimouri, F. Tetrahedron Lett. 2003, 44, 857. (b) Shaabani, A.; Ameri, M. J. Chem. Res. (S) $1998,100$.

[12]. Shaabani, A.; Rezazadeh, F.; Soleimani, E. Monatsh. Fur. Chem. 2008, 139, 931.

[13]. Foroughifar, N.; Mobinikhaledi, A.; Moghanian, H.; Mozafari, R.; Esfahani, H. R. M. Synth. Commun. 2011, 41, 2663.

[14]. Bonne, D.; Dekhane, M.; Zhu, J. Org. Lett. 2005, 7, 5285.

[15]. Pirali, T.; Tron, G. C.; Masson, G.; Zhu, J. Org. Lett. 2007, 9, 5275.

[16]. Parchinsky, V. Z.; Shuvalova, O.; Ushakova, O.; Kravchenko, D. V.; Krasavin, M. Tetrahedron Lett. 2006, 47, 947.

[17]. Dabiri, M.; Bahramnejad, M.; Baghbanzadeh, M. Tetrahedron 2009, 65, 9443.

[18]. (a) Ugi, I.; Meyr, R.; Fetzer, U.; Steinbrückner, C. Angew. Chem. 1959, 71, 386. (b) Ugi, I.; Steinbrückner, C. Angew. Chem. 1960, 72, 268. (c) Ugi, I. Angewandte Chemie International Edition in English 1962, 1, 8. (d) Rossen, K.; Pye, P. J.; DiMichele, L. M.; Volante, R. P.; Reider, P. J. Tetrahedron Lett. 1998, 39, 6823. (e) Shannon, S. K.; Peacock, M. J.; Kates, S. A.; Barany, G. J. Comb. Chem. 2003, 5, 860. (f) Rosenblatt, M. A.; Abel, M.; Fischer, G. W.; Itzkovich, C. J.; Eisenkraft, J. B. Anesthesiology 2006, 105, 217. (g) Domling, A.; Ugi, I. Angew. Chem. Int. Ed. 2000, 39, 3168.

[19]. Cristau, P.; Vors, J.-P.; Zhu, J. Org. Lett. 2001, 3, 4079.

[20]. Bonne, D.; Dekhane, M.; Zhu, J. Org. Lett. 2004, 6, 4771.

[21]. Janvier, P.; Sum, X.; Bienayme, H.; Zhu, J. J. Am. Chem. Soc. 2002, 124, 2560.

[22]. (a) Nasser, I.; Ford, K. Tetrahedron Lett. 1998, 54, 9475. (b) Das, B. C.; Marrippan, G.; Saha, S.; Bhowmik, D.; Chiranjib J. Chem. Pharm. Res. 2010, 2, 113. (c) Wang, S.-Y.; Ji. S.-J.; Loh, T.-P. Synlett 2003, 2377. 
[23]. (a) Pal, R.; Mandal, T. K.; Mallik, A. K. J. Indian Chem. Soc. 2009, 86, 402. (b) Pal, R.; Mandal, T. K.; Mallik, A. K. J. Indian Chem. Soc. 2010, 87, 711 .

[24]. Shiri, M.; Zolfigol, M. A.; Kruger, H. G.; Tanbakouchian, Z. Chem. Rev. 2010, 110, 2250.

[25]. (a) Teimouri, F.; Khezri, S. H.; Miri, Z.; Eftekhari-Sis, B.; Azizian, J. J. Sci. I. A. U. 2009, 19, 103. (b) Pal, R. IOSR J. Applied Chem. 2013, 3, 74 .

[26]. Azizian, J; Teimouri, F.; Mohammadizadeh, M. R. Catal. Commun. 2007, 8, 1117.

[27]. (a) Hassan, S. Y.; Khattab, S. N.; Bekhit, A. A.; Amer, A. Bioorg. Med. Chem. Lett. 2006, 16, 1753. (b) Perumal, R. V.; Mahesh, R.; Bioorg. Med. Chem. Lett. 2006, 16, 2769. (c) Jaso, A.; Zarranz, B.; Aldana, L.; Monge, A. J. Med. Chem. 2005, 48, 2019. (d) Ali, M. M.; Ismail, M. M. F.; El-Gaby, M. S. A.; Zahran, M. A.; Ammar, T. A. Molecules 2000, 5, 864.

[28]. Darabi, H. R.; Tahoori, F.; Aghapoor, K.; Taala, F.; Mohsenzadeh, F. J. Braz. Chem. Soc. 2008, 19, 1646.

[29]. (a) Hays, S.; Rice, J. M. J.; Ortwine, D. F.; Johnson, G.; Schwarz Z. D.; Boyd, D. K.; Copeland, L. F.; Vartanian, M. G.; Boxer, P. A. J. Pharm. Sci. 1994, 83, 1425. (b) Hotchinson, J.; Chua, M. S.; Browne, H. L.; Trapani, V. J. Med. Chem. 2001, 44, 1446. (c) Mathis, C. A.; Wang, Y.; Holt, D. P.; Huang, G. F.; Debnath, M. L.; Klunk, W. E. J. Med. Chem. 2003, 46, 2740.

[30]. Maleki, B.; Salehabadi, H. Eur. J. Chem. 2010, 1, 377.

[31]. (a) Basu, M. K.; Becker, F. F.; Banik, B. K. Tetrahedron Lett. 2000, 41, 5603. (b) Sridharan, V.; Karpagavalli, M.; Muthusubramanian, S.; Sivasubramanian, S. Indian J. Chem. 2004, 43B, 2243.

[32]. Lin, W.; Zhang, X.; He, Z.; Jin, Y.; Gong, L.; Mi, A. Synth. Commun. 2002, 32, 3284

[33]. Sridhara, M. B.; Srinivasa, G. R.; Gowda, D. C. Synth. Commun. 2004, 34, 1441.

[34]. Shaabani, A.; Ameri, M. J. Chem. Res. (S) 1998, 100.

[35]. Anjum, R., Sultan, S. Int. J. Res. Pharm. Biomed. Sci. 2012, 3, 1567.

[36]. Abdullah, J.M., Suliman, M.M. Iraqi National J. Chem. 2011, 43, 418

[37]. Mohite, P.B., Pandhare, R.B., Khanage, S.G., Bhaskar, V.H. Digest J. Nano. Biostructures 2009, 4, 803.

[38]. Kuethe, J.T., Gauthier, D.R., Beutner, G.L., Yasuda, N. J. Org. Chem. 2007, 72, 7469.

[39]. Mahalingam, S.M., Krishnan, H., Patf, H.N. J. Chilean Chem. Soc. 2009, 54, 89.

\section{AUTHORS' BIOGRAPHICAL DATA}

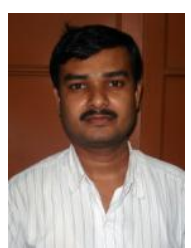

Rammohan Pal was born in 1978 in Kolkata, India. He obtained his B.Sc. in 1999 and M.Sc. in 2001 in Chemistry from University of Calcutta, India. He worked as a DBT-project fellow at the Biological Department of Chemistry, Indian Association for the Cultivation of Sciences (IACS), Kolkata and as a UGC-JRF at the Natural Product Laboratory, Indian Institute of Chemical Technology (IICT), Hyderebad, India. He carried out his predoctoral research work at the Department of Chemistry, Jadavpur University under the supervision of Prof. Asok Kumar Mallik. He received his Ph.D. degree in 2011 from Jadavpur University on synthesis and reactions of some nitrogen heterocycles. He has published over 20 scientific papers. His current research interests cover the development of synthetic methodology, green chemistry and synthesis of heterocyclic compounds. Presently, he is an Assistant Professor of Organic Chemistry at the Acharya Jagadish Chandra Bose College, Kolkata, India. 